Nouveaux cahiers de la recherche en éducation

\title{
Appel à contributions
}

Volume 15, numéro 2, 2012

URI : https://id.erudit.org/iderudit/1018800ar

DOI : https://doi.org/10.7202/1018800ar

Aller au sommaire du numéro

\section{Éditeur(s)}

Faculté d'éducation, Université de Sherbrooke

\section{ISSN}

1911-8805 (numérique)

Découvrir la revue

Citer ce document

(2012). Appel à contributions. Nouveaux cahiers de la recherche en éducation, 15(2). https://doi.org/10.7202/1018800ar d'utilisation que vous pouvez consulter en ligne.

https://apropos.erudit.org/fr/usagers/politique-dutilisation/ 
Revue scientifique francophone sous la responsabilité de la Faculté d'éducation de l’Université de Sherbrooke

\section{Appel à contributions}

- Articles de provenance variée du Canada et de l'étranger

- Deux numéros par année

- Revue scientifique arbitrée

La revue Nouveaux c@hiers de la recherche en éducation invite les professeures, professeurs, étudiantes et étudiants des cycles supérieurs œuvrant dans les différents champs de la recherche en éducation à soumettre des articles pour publication en 2013-2014.

Pour connaître les normes de publication de la revue ou pour consulter les numéros précédents, consultez: http://ncre.educ.usherbrooke.ca/ ou écrivez à ncre@usherbrooke.ca. 